\title{
JOVENS: escola, futebol e projetos de vida
}

\author{
Bruno Martins Ferreira? \\ Osmar Moreira de Souza Junior² \\ Luana Zanotto 3 \\ Fernando Donizete Alves ${ }^{4}$
}

\section{RESUMO}

Esse artigo buscou compreender os projetos de vida de 11 meninos entre quinze e dezesseis anos, estudantes do primeiro ano de ensino médio de uma escola estadual situada em São Carlos-SP. De abordagem qualitativa, se utilizou questionários e formação de grupos focais para a coleta dos dados. Os resultados foram organizados em quatro categorias de discussão: i) "significado de ser jovem", ii) "significação da escola na vida dos jovens", iii) "significado do futebol na vida dos jovens" e iv) "jovens, projetos de vida, crenças e desejos sobre o futuro". Os participantes apontaram a escola como base em seus futuros, legitimando o cumprimento do ciclo regular na ideia de ser "alguém na vida". Somado a isso, o futebol foi significado como modo de socialização, paixão, lazer e sonho, sendo visto como possibilidade de valorização pessoal, social e financeira, embora deflagrada a dificuldade de tal desejo ser sustentável em relação a crença dos próprios jovens.

Palavras-chave: Projeto de Vida. Futebol. Escola.

1 Mestrando em Educação. Universidade Federal de São Carlos (UFSCar). São Carlos/São Paulo, Brasil.

E-mail: brunomartinsufscar@hotmail.com

2 Doutor em Educação Física. Professor do Departamento de Educação Física e Motricidade Humana da Universidade Federal de São Carlos (DEFMH/ UFSCar). São Carlos/São Paulo, Brasil. E-mail: osmar@ufscar.br

3 Doutoranda em Educação. Universidade Federal de São Carlos (UFSCar). São Carlos/São Paulo, Brasil. E-mail: luanazanotto@yahoo.com.br

4 Doutor em Educação Escolar. Professor Departamento de Educação Física e Motricidade Humana da Universidade Federal de São Carlos (DEFMH/UFSCar). São Carlos/São Paulo, Brasil. E-mail: alves.sommer@gmail.com. 
YOUNG: school, soccer and projects of life

\begin{abstract}
This article presents the life projects of male adolescents in the first year of high school of a public state school in São Carlos, SP, Brazil, their relationships and roles assigned to school and to football. The answers to a questionnaire enabled the subject classification into two focal groups which were conducted towards the understanding of the research goals. The results were divided into four categories: i)"meaning of being young," ii) "meaning of school in young people life", iii) "meaning of soccer in young people life" and iv) "young people, life projects, beliefs and desires about the future". Participants pointed the school as their future basis, legitimating the fulfillment of the regular cycle aiming to be "someone in life". In addition, football meant: socialization, passion, pleasure, dream, and it could be seen as personal, social and financial appreciation, although it triggered the difficulty of such desire to be sustainable over their own belief.
\end{abstract}

Keywords: Projects of Life. Soccer. School.

\title{
JÓVENES: escuela, fútbol y proyectos de vida
}

\section{RESUMEN}

Este artículo busca la comprensión de proyectos de vida de 11 chicos con edad entre quince y dieciséis años, estudiantes de primer año de enseñanza media de una escuela pública situada en São Carlos-SP. De enfoque cualitativo, ha sido aplicado un cuestionario en secuencia por la formación de grupos focales. Los resultados fueron organizados en cuatro categorías: i) "significado de ser joven", ii) "significación de la escuela en la vida de los jóvenes", iii) "significado del fútbol en la vida de los jóvenes" y iv) "jóvenes, proyectos de vida, creencias y deseos sobre el futuro". Los participantes señalan la escuela como base en sus futuros, legitimando el cumplimiento del ciclo regular en la idea de ser "alguém na vida". Añadido a esto, el fútbol es considerado como medio de socialización, pasión, ocio y sueño, siendo visto como posibilidad de valorización personal, social y financiera, aunque los jóvenes siguen viendo complicado hacer sostenibles sus deseos.

Palabras clave: Proyecto de Vida. Fútbol. Escuela. 


\section{INTRODUÇÃO}

O presente estudo buscou compreender os sentidos que os jovens estudantes do Ensino Médio atribuem ao futebol e à escola, em uma perspectiva de projetos de vida. Buscamos entrelaçar as relevâncias sociais, bem como alguns valores individuais importantes, como a responsabilidade social e as perspectivas críticas assumida na vida destes jovens.

O sentido de jovens apresentado neste estudo superou a dimensão exclusiva da condição de aluno, ou seja, os meninos, em especial, foram entendidos como pessoas em sua totalidade. Neste sentido, concordamos com Leão, Dayrell e Reis (2011, p.1068) ao dizerem que

[...] o ser aluno aparece como um dado natural e não como uma construção social e histórica. O momento da fase de vida e suas peculiaridades, a origem social, o gênero e a etnia, entre outras dimensões que o constituem como jovem, não são levados em conta e constroem a vida do aluno fora da escola como um tempo vazio de sentido, um não tempo.

Assim, reconhecemos que os jovens atribuem significados às práticas que dão sentido às suas vidas, e não somente ao futebol - objeto de investigação deste estudo e também por ser largamente difundido na vida dos brasileiros por aspectos histórico-sociais - mas, por considerar que a prática do futebol assume um papel relevante na vida dos jovens meninos em idade escolar.

Os veículos midiáticos, por suas vezes, contribuem para que os garotos cada vez mais tenham uma compreensão de que a carreira profissional de um futebolista é glamourosa, com status de êxito e de alto reconhecimento social. Contudo, em diálogo com a prática que se verifica na escola, o modelo de formação de profissionais de futebol desconsidera os saberes dos jovens, assim como seus contextos de vida, em prol do cumprimento dos objetivos que o sistema educacional estabelece, todavia com modelos de formação para a produção.

Outro ponto de vista que comunga da lógica de formação para produção, aponta o descaso dos centros esportivos, popularmente conhecidas como "escolinhas", acerca do processo de formação da carreira esportiva. Segundo Damo (2007, p. 169), "os meninos em formação não são ventrílocos de quem quer que seja. São sujeitos, como outros quaisquer, empenhados na realização de seus projetos, referidos seguidamente como sonhos".

Com esses apontamentos, os modelos de concepção sobre o jovem corroboram com a disseminação em massa de informações desconexas com a realidade em que estão inseridos, ou seja, ao invés de auxiliar circunstâncias aliadas às lógicas de formação crítico-participativo na sociedade, conduz os jovens a não se apropriarem de conhecimentos e informações representativas e significativas para o cotidiano. Assim, destacamos a relevância em entender quais são os projetos de vida desses meninos.

Valemo-nos das ideias de Velho (1987) citado por Souza Júnior (2013, p.27) para compreender o termo projetos de vida. Para o autor: 
Projeto é uma perspectiva racional de perseguir finalidades específicas, ligado à forma como um indivíduo opera com o desempenho e as opções assentadas nas avaliações da realidade em um dado contexto sociocultural. Projetos são formulados pelos indivíduos que se movem, combinando pressões sociais diversas, mas com um repertório básico de alternativas e opções que configura o campo de possibilidades para agir e planejar projetos de vida.

Assim, debruçar-se na investigação de quais são os projetos de vida de jovens do ensino médio se mostra relevante para entender a que lógica estes projetos estão submetidos. Do mesmo modo, para compreender como os adolescentes mobilizam e investem para conseguirem alcançar seus sonhos relacionados ao universo futebolístico e, sobretudo, a que custo. Para tanto, delineamos algumas questões de estudo: como jovens meninos significam a escola e o futebol em suas vidas? Podemos falar em projetos de vida, uma vez que esses talvez não tenham um contexto gerador de possibilidades para pensar um projeto de vida, mas sim em que apenas vivam o presente significando a realidade?

Nestas perspectivas, o objetivo principal do presente estudo foi compreender os projetos de vida de jovens meninos do primeiro ano de Ensino Médio, em especial em relação aos papéis atribuídos à escola e ao futebol. Na perspectiva de jovens/sujeitos, pretendemos compreender os anseios e as atitudes relacionais com o futebol e à instituição escolar em seus modos de projetar seus futuros.

\section{O jovem e o futebol na sociedade}

O jovem é tomado por um intenso contexto de conflitos, por vezes, internos, ao emancipar-se humanamente nos sistemas econômicos, políticos e ideológicos; ou a pensar em suas futuras profissões, inserção social, e ainda por travar embates com o mundo em que vive e suas relações para com ele. Peralva (1997) ressalta que a juventude é, ao mesmo tempo, uma condição social e um tipo de representação. A autora entende que para além de um processo transitório, em que independente de traduzir seus sonhos em ações concretas, somente o fato de expressar os mesmos, já parece ser muito significativo. Este paradoxo se agrava, pois a maioria das explicações para os jovens são insatisfatórias.

O olhar da sociedade de modo geral é depreciativa para com os jovens. Em Dayrell (2003, p 40-41) temos:

[...] nos deparamos no cotidiano com uma série de imagens a respeito da juventude que interferem na nossa maneira de compreender os jovens. Uma das mais arraigadas é a juventude vista na sua condição de transitoriedade, na qual o jovem é um "vir a ser", tendo no futuro, na passagem para a vida adulta, o sentido das suas ações no presente vivido. Sob essa perspectiva, há uma tendência de encarar a juventude na sua negatividade [...].

Em meio a esse processo transitório de vir a ser, o jovem desenvolve sensações e percepções exacerbadas em seu contexto de vida, como suas emoções, descobertas, 
formulações de ideias, e vários questionamentos que lhe tomam de angústia e anseiam por respostas, como: “Quem sou?", "Para onde vou?”, "O que fazer da vida?", “Quando crescer vou ser o que quero ou o que dá para ser?" Conforme Leão, Dayrell e Reis (2011), estes questionamentos constituem uma dimensão decisiva no seu processo de amadurecimento.

Por vezes, os jovens sentem dificuldades em significar o futuro, até porque o que Ihes é concreto hoje é somente seu presente e, muitas vezes, pelas influências culturais e familiares que não o convidam a pensar em situações que projetem seus sonhos e expectativas, de modo a configurar um quadro em que a culpa do "amanhã" não desejado é jovem que nunca se preocupou. Neste ínterim, é importante ressaltar que o sentimento de culpabilização deve ser minimizado entre os jovens, ao entender em Dayrell (2003) que quando cada indivíduo nasce a sociedade já tinha uma existência prévia, histórica, cuja estrutura não dependeu desse sujeito, portanto, não foi produzida unicamente por ele.

A partir dessa contribuição podemos refletir em relação aos cenários e propostas de vida que se apresentam aos jovens, assim como aos ambientes comuns a eles, sendo o ambiente escolar um dos mais gerais a todos. Assim, o modo efetivo de existência de um jovem na escola também perpassa a várias outras interrogativas, como bem apresentam Ferreira et al. (2010, p.3):

A esse respeito, curiosamente, interrogações vem se mostrando cada dia mais acen-
tuadas, quais sejam: Quem é o jovem que está na escola? O que eles pensam sobre
a escola? O que vem afastando os jovens das aulas? O que eles pensam? Qual a
relação destas aulas com o cotidiano deles? Que sentido eles lhes atribuem?

A compreensão dos papéis da escola e do futebol nos projetos de vida dos jovens prescinde análise sobre qual é o papel atribuído por esses sujeitos às instituições. Tal investigação também se pauta em como os meninos significam e atribuem sentido a prática esportiva do futebol, pois partindo do pressuposto do futebol ser a prática mais difundida em nosso país, este esporte encontrou no Brasil um tipo de residência fixa, agregando a ele, torcedores, consumidores, o fanatismo e os críticos.

Ainda em contexto brasileiro, o futebol também é tido como profissão, embora na grande maioria dos casos seja dificílimo pensar futebol como projeto profissional, tanto para homens quanto para mulheres, por consequência de fatores que seguem impedindo o direito dessa prática esportiva, justificadas pelas péssimas condições de trabalho e também pelos os contratos instáveis e baixa remuneração. No mesmo sentido, Souza Junior (2003, p. 23) explica que o futebol enquanto fenômeno social:

[...] atraia um público crescente e o status de importância dos clubes, que concentravam interesses financeiros cada vez maiores, dependia do desempenho de suas equipes futebolísticas. Para tal, foi necessário recrutar jogadores das camadas mais baixas, nas quais havia jogadores talentosos, que praticavam o futebol com dedicação, e nele viam um canal de ascensão social.

Muitas vezes, após cumprirem suas obrigações em período escolar, os meninos jogam futebol nas ruas, em espaços de educação e lazer, tais como clubes, centros 
esportivos ou até mesmo na própria escola em turmas de treinamento no contra turno ou em aulas de Educação Física. Com a verificação assídua da prática do futebol, configuramos como objeto de estudo compreender junto aos jovens meninos se veem no futebol uma perspectiva de carreira, mesmo se não indicando carreira, mas quantos desses já não pensaram em ser Neymar, Cristiano Ronaldo, Messi ${ }^{5}$. Assim, o que esses meninos investem atrás desse sonho, arquitetados ou não como projetos de vida é a tônica para também entender a forma como interpretam e significam o futebol em suas vidas.

Damo (2007) expõe a face oculta de uma profissão que exige altos investimentos em termos de tempo e energia, em que jovens meninos precisam se submeter para ingressar nesse universo - muitas vezes motivados por uma ascensão social. Segundo Giglio et al. (2008), tal ascensão é alimentado pelo imaginário coletivo que institui a ideia de que os profissionais de futebol acumulam fortunas às custas apenas de um suposto talento ou dom que acreditam ter recebido como uma dádiva divina. Em contrapartida, pouco se trata que a carreira é curta, já que o auge vem na contra mão de outras carreiras profissionais em que as restrições laborais são severas, somada à iminente dificuldade de "reconversão", ou seja, a relocação de um ex-futebolista no mercado de trabalho.

Na prática, os jovens meninos não chegam às equipes profissionais com um déficit de capital futebolístico, mas sim com lacunas na formação escolar, o que acarreta à reflexão sobre até que ponto o sentido existente para eles faz sentido para quem tem o discernimento de avaliar todo um processo de investimento em que são dedicadas mais de 5.000 horas de treinamento. Em via de regras, para na maioria dos casos não se conseguir prosperar nesse projeto de vida (DAMO, 2007).

Pensar os sentidos que o jovem atribui à escola e para a prática do futebol são esferas primeiras para pensar os projetos de vida. Nesta ótica de co-elaboração teórica, por projetos de vida, Leão, Dayrell e Reis (2011, p. 1071-1072) definem:

\begin{abstract}
A ideia de projeto de vida remete a um plano de ação que um indivíduo se propõe a realizar em relação a alguma esfera de sua vida (profissional, escolar, afetivo etc.) em um arco temporal mais ou menos largo. Tais elaborações dependem sempre de um campo de possibilidades dado pelo contexto socioeconômico e cultural no qual cada jovem se encontra inserido e que circunscreve suas experiências.
\end{abstract}

Assim, os projetos de vida atendem a realizações tangíveis e certamente já influenciadas pelo que os indivíduos apresentam por base em suas experiências de vida. Não se trata de algo simples; ao contrário, emergem como problemáticas exponencialmente crescentes e que, por vezes, nem ao certo se tem um prazo para que as soluções sejam efetivas.

Mais uma vez, Leão, Dayrell e Reis (2011) trazem à luz o contexto de inserção em que os projetos de vida devem ser entendidos por diferentes perspectivas e posturas, ou seja, como a busca de estratégias construídas para lidar com o contexto em que se formam e no qual se encontram. Da mesma forma, com os recursos materiais e subjetivos a que

5 Nomes de destacados jogadores profissionais de futebol, mundialmente conhecidos. 
possuem acesso, "[...] interferiam diretamente na capacidade de lidar com o futuro, em um contexto social dominado pelas incertezas [...]" (p. 1078).

Reconhecemos que as ações dos indivíduos são limitadas pelo campo de possibilidades. Todavia, a sua vida e o que nela ocorre não se limitam, pois cada trajetória é singular e distinta de outra. Cada sujeito assume distintas posturas de ação e reflexão frente ao mundo. Neste sentido, o jovem é ser antes de tudo "ser". Isto dá sentido em sua vida e está intimamente ligado com o seu "vir a ser", ou seja, com os seus projetos de vida. Entender os meninos na escola, as significações atribuídas ao futebol e o que pensam para o futuro, destarte é entender as várias gerações e as que ainda estão por vir.

\section{TRATAMENTO METODOLÓGICO}

A pesquisa foi desenvolvida com enfoque qualitativo (BOGDAN; BIKLEN, 1994), abordagem que interpreta a realidade e o contexto social do indivíduo, atribuindo ao enfoque investigado um caráter minucioso de apreensão dos gestos e expressões, comportamentos e atitudes dos investigados. Foi realizada junto a todos os meninos de duas turmas do primeiro ano do Ensino Médio, de uma escola pública estadual da cidade de São Carlos. A priori, foi elaborado um questionário para que a escolha dos perfis para participação do próximo método - grupo focal - fosse compatível com a proposta de pesquisa.

Assim, utilizamos o grupo focal como instrumento metodológico, atendendo aos critérios de características comuns entre tais sujeitos, qualificando-os assim para a posterior discussão das interrogativas que pertencem a investigação (GATTI, 2005). A homogeneidade do grupo focal foi assegurada com o cuidado necessário na seleção de perfis, em que se buscou identificar as mais relevantes respostas dos questionários e suas informações para o entendimento e cumprimento de objetivo da investigação.

Os perfis delimitados para a composição do grupo apresentaram como característica comum o pensamento de algum dia ser jogador de futebol. Após tal característica comum aos perfis desejados, perguntávamos em uma escala quantitativa de 0 a 10 sobre o gostar da escola e de futebol, sendo necessária a justificativa da menção. Tais medidas auxiliaram na decisão final da composição do grupo focal.

Assim, elegemos enquanto sujeitos desta pesquisa 11 jovens com idade entre quinze e dezesseis anos. Todos eles pertencentes às famílias de trabalhadores assalariados, em sua maioria empregada por empresas de diversos setores, todas situadas na mesma cidade. Parte dos membros do grupo são filhos de micro empresários na mesma cidade. Todos os jovens sem exceções cumpriram seus ciclos escolares em escolas públicas, sendo que desses a maior parte residem nas proximidades da escola. Trata-se de um bairro central, sendo a escola referência de qualidade para o ensino público da região.

Em conversas informais, quatro meninos disseram trabalhar em empregos formais no contra turno do período escolar. Outros três, também no contra turno dedicavam-se aos estudos de cunho técnico oferecido pela própria instituição. O restante do grupo pertencia às turmas de treinamento de futebol ofertadas por clubes da cidade. 
A escolha por aplicar o questionário somente aos meninos se justifica pelo respaldo cultural que o futebol tem no Brasil, onde, em um primeiro plano, a prática hegemonicamente é relacionada ao jogo entre homens. Souza Júnior (2013) indica outro fator que auxiliou na designação dos sujeitos em pesquisa, o fato da falta de coerência de cumprimento da legislação, que prevê o tratamento uniforme para atletas futebolistas indiferente de gênero. Porém, o futebol feminino no Brasil vem sido tratado ao longo de sua história como amador, o que culmina com as quase nulas pretensões de se tornar futebolistas por parte das meninas, que não vislumbram tal profissão como projeto de vida sustentável.

Para o grupo focal, os participantes foram divididos em dois segmentos, com perfis similares e distintos, numa espécie de comunhão em predileção e diferença nas visões. Cada sessão de grupo focal foi gravada em áudio por meio de um aparelho de gravador de voz digital. Todas as sessões foram realizadas na mesma escola em que os alunos estão matriculados, em um local próximo ao portão de saída, em que foi possível a formação de roda entre os participantes, bem como o isolamento para com o restante da escola, por ser entendido como um local tranquilo e com boas condições de privacidade e silêncio para o melhor desenvolvimento dos grupos. O horário para estes momentos se deram durante as respectivas aulas de Educação Física das duas turmas dos sujeitos da pesquisa, ocorrendo uma semana após a aplicação do questionário, contando com a colaboração do professor de Educação Física que disponibilizou um tempo de suas aulas para aplicação do questionário.

Os grupos focais ocorreram no mesmo dia para que a comunicação entre os alunos do primeiro ano da escola de turmas diferentes não existisse. Como as duas turmas dos primeiros anos tinham aula em sequência, houve o cuidado para que os garotos do primeiro grupo não antecipassem as interrogativas do grupo posterior, assim tendendo a não influenciar, preparar ou formatar qualquer tipo de resposta a uma pergunta já sabida.

Após a coleta dos dados, os mesmos foram transcritos na íntegra. Em sequência da transcrição do grupo focal, houve a análise por meio de leitura e releitura, para formação de categorias temáticas em consonância com os objetivos propostos. Para a análise de dados a abordagem metodológica elegida foi a análise de conteúdo. Bardin (1979) traz que tal análise visa obter indicadores quantitativos e qualitativos, que permitam inferir os saberes relativos às condições de produção das mensagens. Os diálogos emergidos dos grupos focais foram explorados por meio de uma nova leitura, a qual permitiu identificar elementos e unidades de registro que possibilitaram a formação de quatro categorias de análise, as quais serão apresentadas e discutidas no item seguinte deste artigo.

Salientamos que foram respeitados todos os cuidados éticos no que se refere ao consentimento de participação (foi entregue aos participantes o Termo de Consentimento Livre e Esclarecido) e ao anonimato das identidades, por meio de nomes fictícios e à confidencialidade dos dados.

\section{RESULTADOS E DISCUSSÕES}

A primeira categoria identificada tratou de analisar o significado de ser jovem, sua identidade e o modo peculiar de como se veem. A segunda categoria diz respeito à 
significação da escola na vida dos jovens e suas motivações para com os estudos. A terceira, por sua vez, tangenciou a significação do futebol na vida dos jovens. Com a última, buscamos analisar o desejo e a crença do que virão a ser, as projeções e projetos de vida dos jovens pesquisados nessa investigação.

\section{Significado de ser jovem}

A compreensão do ser jovem necessita transcender a perspectiva de entendimento da identidade juvenil, pois essa é dotada de características estanques e descritivas, que pouco reconhece o papel ativo do jovem no processo de construção cultural, necessitando o jovem ser compreendido, segundo Ferreira et al. (2010) em sua esfera sociocultural. Neste sentido, para os participantes do grupo focal, ser jovem é antes de tudo aproveitar a vida, suas oportunidades, desfrutar o fato de estar na flor da idade, saber aproveitar os momentos, tendo em vista seu alto vigor físico e disposição.

De modo geral, as visões de mundo dos participantes nos permitem compreender que eles integram uma fase de maturação da personalidade, ao mesmo tempo em que são sabedores de suas posições na sociedade, principalmente no que diz respeito à aproximação da fase adulta, indicando que, tal período marca o início de uma fase com mais obrigações e pressões sociais.

Quando perguntados "o que significa ser jovem para vocês?", Bebeto ${ }^{6}$ diz: "É viver sem reponsabilidades, ainda que tendo. Já já eu tenho a idade do meu pai quando ele se casou", enquanto que outro rapaz, Romário responde que: "É fazer várzea né, enquanto dá tempo. É ter liberdade pra aproveitar a vida" (sic). Com a fala do garora, Dayrell (2003) indica que a juventude é vista pelos próprios atores como um tempo para o ensaio e o erro, marcado pela irresponsabilidade e muito disso pode ser creditado pelas experiências anteriores dos pais.

Os jovens tomam como exemplo a vida adulta e regrada que os pais têm em conjunto aos discursos orientadores de seus núcleos familiares, que pregam em linhas gerais, que esses jovens estão na melhor idade, mas que concomitantemente estão na hora de não errar mais. Nesse ponto existe um grande paradoxo, o da criação e da geração. Ferreira et al. (2010, p. 6) em estudo sobre "O ser jovem para o próprios (aluno) jovens" trazem o pensamento dos jovens sobre seus pais:

Eles dizem que a geração dos avós deles era muito repressora, e que muitos pais tiveram que trabalhar desde cedo e por isso veem os filhos como irresponsáveis e sem preocupações. Falam ainda que quando os pais deles eram jovens não havia muitas coisas para fazer como há hoje.

6 Para designação e garantia de integridade dos jovens colaboradores entrevistados, foi utilizado nomes de futebolistas brasileiros com destaque mundial. 
Assim, os jovens sentem seus pais longes da realidade e experiências que eles vivenciam hoje, da real ideia para eles de aproveitamento do mundo à sua volta, da empolgação, do entendimento de liberdade e da diversão. O "ser eu mesmo" do ser jovem poderia ser entendido pelo enfoque cultural, para além de uma margem etária que compreende dos quinze aos vinte e quatro anos de um dado período transitório.

O ser jovem carece da compreensão de suas visões de mundo, sentimentos emoções, desejos, maneiras de se vestir, falar, portar, seus projetos e formas de sociabilidade (FERREIRA; SILVA; GOES, 2009). Os jovens se constroem, são detentores de seus próprios modos de ser, suas identificações e identidades, reveladas sempre nas relações de seus contextos sócio-históricos com o mundo que segue em fluidez se apresentando a ele. Sobre isso, a categoria a seguir aborda a escola na vida dos jovens, entendendo como os meninos compreendem a escola em suas vidas.

\section{Significação da escola na vida dos jovens}

Pensar a escola para os jovens é pensar seu futuro, sua preparação para a vida e para "ser alguém na vida". Ao menos é assim que os participantes desta pesquisa expressam a significação da escola em suas vidas. Ainda que somente cinco dos onze componentes do grupo vejam a escola como um modo de "garantir o futuro", termo em comum nas falas dos estudantes, Rocha et al. (2011) traz que as chances de uma carreira melhor sucedida em diferentes áreas da vida adulta passam por um investimento nos estudos.

Mais do que a ideia de satisfação concreta de seus anseios, muitos jovens buscam não depender do "doloroso ônus" do investimento prolongado da formação escolar (FERREIRA et al., 2014) ou apostar em profissões e carreiras em que não se depende de escolarização. Tal constatação estabelece coerência quando analisado os dados da pesquisa de Damo (2007) que indicam que nas escolas públicas da cidade de Porto Alegre, a cada três meninos, um tem o desejo de ser futebolista, permitindo assim verificar que o esporte passa pelos planos e projetos juvenis por também representar uma profissão que não depende de graduações ou diplomas.

Neste sentido, ao perguntar aos participantes "O que motiva vocês a estudar?", novamente os jovens pesquisados respondem "ter um futuro", para justificar a pergunta e a participação assídua na vida escolar. Em contraponto, apenas cinco jovens, em especial, os que cursam a modalidade de ensino técnico oferecido no contra turno, sinalizam que a escola significa/estabelece alguma relação com seus futuros.

A notória diferença entre estes jovens motivados a estudar por uma ideia de futuro e dos que estabelecem com a escola tal relação com seus futuros, talvez esteja no desvelar dos sentidos que os termos "significar", e "motivar" representem a esses jovens. Sendo assim, "significar" representa a relação de reconhecimento, de apreço e importância ligados aos valores intrínsecos das pessoas, enquanto "motivar" é entendido como um processo responsável por direcionar, manter comportamentos relacionados com o cumprimento de objetivos, ligados com fenômenos emocionais biológicos e sociais que envolvem as pessoas. 
Assim consideramos que a percepção das cargas emocionais envolvidas nos discursos - embora a maioria dos jovens entrevistados consiga significar a escola com seus futuros - eles não conseguem definir tal futuro. Todavia, são motivados a cumprir o espaço temporal do "estudar", referente ao ciclo regular de ensino, por cumprir um objetivo comum de curso da vida, justificando a escolarização como alento e segurança em seus porvires. Neste sentido, Kaká pondera: "[...] é saber que sem o estudo eu não vou pra lugar nenhum".

Ainda que algumas instituições escolares brasileiras apresentem precariedade em certos setores, não é incomum constatar visões superficiais de quem por motivos de estágio curricular ou intervenções pedagógicas a frequenta. O sucateamento evidenciado pelos seus prédios e recursos humanos, falta de incentivo aos profissionais docentes somados ao conjunto de normativas adotadas pelo estado que corroboram para um ensino deficitário e uma formação menos humana, auxiliam os jovens em grande medida, a cumprir esse arco temporal formativo/educativo de suas vidas, ainda que sem conseguir significar a escola como caminho exitoso em seus projetos de vida.

Assim, sustentamos este pensamento nos dizeres da UNICEF (2014), ao mencionar que a educação formal do Brasil no que tange o sistema público já não é vista como caminho de ascensão social. Em diálogo, Ferreira et al. (2014) apontam que a ausência de referências de profissionais bem sucedidos alicerçados pela trajetória escolar contribui para que jovens apoiem-se na incerta expectativa de uma ascensão social pelo futebol, em que o valor social que se atribui à escola atual não atende ao imediatismo manifesto do ser jovem e, sincronicamente, fornece uma base educacional que atenua suas incertezas quanto ao futuro, ou garantia desse.

\section{Significado do futebol na vida dos jovens}

Ao tratar da significação do futebol como elemento de socialização, Koch (2012) traz que o futebol é uma cultura em que todos parecem iguais, fazendo com que, pertencendo a essa cultura estejam interconectados ao mesmo universo conceitual e linguístico. Deste modo, ganha relevância a pluralidade de significados destacados nas respostas dos garotos. Mais uma vez o futebol se manifestou e ganhou sentido múltiplo. Para Bebeto e Falcão, o futebol foi significando pelo seu modo de socialização. Já para Kaká e Sócrates como paixão. Descontração e lazer por Vampeta, Renato Gaúcho e Robinho e, por fim, significado como sonho por Rivaldo, Ronaldo, Zico e Romário.

Historicamente em nosso país, o futebol atuou na noção de pertencimento, no reforço dessa espécie de elo, especialmente no tocante as afirmações das virtudes e dos valores masculinos expressos no corpo dos jogadores (SALVADOR, 2009; SOARES, 2011). A formação de grupos sociais, aqueles aos quais se compartilha uma cultura comum é hoje uma forma de reconhecer-se e situar-se na sociedade contemporânea, e a cultura do futebol, por sua vez, permite a existência da socialização por meio de grupos que comungam dessa mesma prática.

Os garotos Kaká e Sócrates, praticantes de treino de futebol em contra turno escolar, têm para si o futebol como paixão. Mediante este sentimento, refletimos que nenhum outro 
esporte mobiliza tanto o brasileiro quanto o futebol, havendo uma criação de alguma coisa na qual o Brasil se reconhece e o mundo reconhece o Brasil.Queríamos antes ser Pelé, depois Maradona e Zico, não muito antes Romário, Zidane, Ronaldo, e assim a ideia do ídolo, do herói de chuteiras também participa para aumentar nosso sentimento pelo futebol.

Hall (1997) entende que no Brasil o futebol é a espinha dorsal da nação, que por vezes permite a queda de barreiras, de classe, de religião, de raça e até mesmo de gênero. Corroborando com o autor, ao pensar nas ferramentas socioeducativas, nada é mais paixão, nem é mais popular em território brasileiro, do que o futebol.

O videogame, por sua vez, é um dos grandes responsáveis por disseminar o esporte. Os jogos eletrônicos "FIFA" e "Pró Evolution Soccer" estão entre os mais vendidos no mercado de games há décadas, e a atualização de novos jogos causam grande expectativa para os amantes de jogos virtuais.

Para outros três meninos, Renato Gaúcho, Robinho e Vampeta, o futebol é indicado como lazer e divertimento. Na fala de Vampeta observamos a seguinte justificativa:

"Descontração. Eu mesmo não tenho muito mais tempo pra brincar né, to ficando velho, as responsabilidades vem chegando, a Magali não alivia (professora de matemática), então quando tem um futebol eu quero é tirar onda, dar relaxo, nem tô ligando se vão reclamar. Eu vou pra dar caneta, pra me divertir, por isso pra mim é lazer, é diversão" (sic).

O protagonismo das pessoas, em especial dos jovens, perpassam muitas vezes por demonstrar competência no que se faz, e satisfação ao fazer. Poder se sentir bem ao discutir com propriedade, interpretar, ver e analisar, saber mais sobre o assunto, manipular exitosamente por outros meios, como os games, futebol de botão, pebolim, até mesmo ao jogar, não na vertente do alto nível de competição, e sim na ideia de se permitir desfrutar do que se está fazendo/jogando.

Estes modos são meios paralelos de como os jovens conseguem satisfazer suas necessidades de divertimento e lazer, na perspectiva de um ócio produtivo relacionado ao futebol. Koch (2012, p. 22), alicerça a ideia da presença do futebol corrente na vida dos brasileiros, e sua relevância social sustentada pela própria relação que temos com o esporte. Para o autor

[...] a Informídia, empresa especializada em pesquisas sobre retorno de mídia no esporte, divulgou um de seus estudos quantitativos sobre os espaços que cada modalidade esportiva possui na televisão brasileira. Nesta pesquisa, o futebol ocupa a maior faixa, com uma porcentagem que ultrapassa os $65 \%$, considerando apenas a programação esportiva. Em outro dado de outra pesquisa - esta encomendada pela cervejaria Heineken -, realizada com mais de cinco mil pessoas de 15 países sobre a importância do futebol na vida dos homens, o Brasil aparece em segundo lugar, perdendo apenas para os ingleses.

Como última frente de resposta, em predominância pelos jovens, o futebol significa "o sonho". Para quatro garotos, Rivaldo, Romário, Robinho e Ronaldo, futebol foi 
referenciado como conjunto de pensamentos, imagens e fantasias de um futuro sem a seguridade de sua concretização. O menino Ronaldo, sumariza a concepção de futebol como sonho. Em suas palavras: "[...] é o sonho né, o melhor esporte que tem, é sonho é paixão, é o lugar onde eu queria, e acho muita gente queria estar" (sic).

Segundo Souza Júnior, Ferreira, Coutinho Netto (2013), os garotos demonstram uma paixão e sonho pelo futebol que se confunde com as reais chances de seguir na profissão de futebolista, muito devido a falta de postos de trabalho bem remunerados, o processo não dependente de atributos futebolísticos, e a relevante presença de um empresário para intermediar as potenciais futuras carreiras. Trata-se de elementos que Damo (2007) utiliza para refletir que o procedimento de transformação de jovens garotos em futebolistas tem uma estrutura muito mais complexa do que a fantasiada ideia glamourosa e de status que o imaginário coletivo comum propaga.

Por conseguinte, Ferreira et al. (2014) tendem a tornar difusas suas interpretações em relação aos projetos de vida, em que frequentemente os seus discursos expressam alusões a seus sonhos e desejos. Em consonância, para Koch (2012, p. 127):

O futebol é uma ferramenta que constrói as mais variadas mercadorias, podendo ser estas, tanto as celebridades do 'mundo da bola', como um número incontável de crianças e jovens que produzem seus corpos de forma a serem valorizados e consumidos nessas sociedades futebolizadas.

Assim como construtor de mercadorias, o futebol opera à lógica da construção de sonhos, pela produção e incorporação de jovens que pensam na possibilidade de valorização pessoal, social e financeira por intermédio do esporte. Para além disso, o futebol apresenta-se como meio à carreira profissional exitosa e nutre a ideia do reconhecimento social, como pouco frequente é apreciado em atletas vinculados às outras modalidades esportivas.

Com isso, chegamos à discussão da última categoria de análise apresentada em seguida, que analisa o desejo e a crença destes jovens sobre o que futuramente serão, destacando seus projetos de vida relacionados ao futebol.

\section{Jovens, projetos de vida, crenças e desejos sobre o futuro}

Após uma breve explicação acerca dos conceito e das compreensão de projetos de vida, foi perguntado aos garotos se eles tinham algum projeto de vida ${ }^{7}$. Enquanto dificuldade apresentada às respostas ao questionamento, destacamos o constrangimento dos meninos, por observar que cinco preferiram não emitir opiniões sobre o assunto. Nestas circunstâncias, não podemos afirmar que a omissão é consequência do desconhecimento

7 Consideramos a não existência de avaliação se tais jovens conseguiram distinguir de forma clara e objetiva o significado de projetos de vida 
sobre o que é projeto de vida. Ponderamos que os garotos nunca antes tivessem confrontados com tal indagação, a julgar por suas expressões faciais, gestos corporais e troca de olhares entre si.

Por outro lado, os que se manifestaram concentraram os sabres nas facetes nas vivências tidas no presente atrelado às perspectivas futuras. Nas falas de Sócrates, Kaká e Romário, respectivamente, temos:

"Estudar sempre que possível porque têm né, e treinar o futebol, para ter uma garantia de que alguma coisa você vai conseguir. Enquanto não viro jogador, isso focar mais nos estudos, para conseguir um emprego".

"O que eu to fazendo hoje porque eu quero amanhã, eu to me dedicando aos treinamentos para ver se eu consigo passar numa avaliação e ficar alojado num time. É o que eu to fazendo hoje, para um futuro de amanhã. Se caso nada disso der certo, eu começo a estudar que nem louco pra entrar numa faculdade pra ser bancário".

"Quero terminar os estudos e, se eu me decepcionar com o futebol assim, se eu não conseguir, é abrir uma escolinha pra tentar realizar o sonho de outras pessoas que tiveram o mesmo sonho que eu".

Entre as distintas respostas ofertadas pelos jovens participantes, as três acima evidenciam nos projetos de vida a ideia de converter-se em futebolistas é verídica e anseia pelo futuro. Mais do que isto, notamos um investimento temporal, e ainda que não muito esclarecido, a caracterização de um plano de ações para que se tornem jogadores de futebol, o que se configura como projetos de vida.

Observamos que a ideia de investimento nos estudos escolares é contemplada pelos meninos, porém configura-se como plano alternativo em casos de "decepção com o futebol", "se nada der certo", "estudar [...] enquanto não viro jogador" (Kaká e Sócrates). Sendo assim, o estudo e sua importância afloram no reconhecimento da necessidade de uma formação escolar para captação de recursos financeiros e colocação no mercado de trabalho, seja para abrir uma escolinha, ser bancário ou trabalhar com informática. Nesta discussão, novamente ilustramos que a educação escolar não é vista pelos estudantes como possibilidade de ascensão social, mas sim como modo de garantias mínimas caso suas buscas sejam frustradas, neste caso, se a profissão de jogar dor for frutífera.

No estudo de Ferreira et al. (2014), houve a constatação alarmante no que diz respeito a importância que a escola e os estudos têm para a arquitetura de seus respectivos projetos de vida. De quatorze futebolistas da equipe sub 17 de um clube de futebol do interior do Estado de São Paulo, oito rapazes indicaram preferir repetir um ano escolar a perder uma final de campeonato, indicando o tentador atalho que o futebol apresenta como ascensor social. Ainda que muitos desses jovens se convertam em futebolistas é imprescindível que eles tenham garantias de direito e acesso a outras possibilidades e escolhas, pois, meninos de quinze e dezesseis anos são seres sociais, passíveis de transformações físicas, psicológicas, cognitivas e valorativas, por isso é preciso que existam 
outros caminhos, caso haja mudança de opinião, tropeços, frustrações ou impedimentos, na realização de seus projetos.

Tamanha incerteza do futuro foi também percebida pelas respostas, sobretudo às previsões do que se imaginam fazendo daqui cinco anos. Três garotos, Zico, Kaká e Falcão se imaginam de fato estudando em uma faculdade, enquanto Juninho Rivaldo e Falcão pensam estar em algum clube de futebol jogando bola ou na universidade, e os outros cinco participantes não souberam dizer.

Por fim, uma espécie de provocação em forma de perguntas foi levada ao grupo focal. O que eles querem ser quando chegarem a fase adulta? O que eles acreditam que serão quando nessa fase chegarem? As interrogativas foram feitas separadas, motivado pela tendência de reflexão que os meninos teriam que fazer, ao pensar em suas respostas, pois o ponto de partida se deu no pressuposto de que existe por múltiplas razões para a incoerência entre os desejos e as crenças, o acreditar e o querer, as limitações dos horizontes e a força de vontade.

Dos onze entrevistados, Kaká, Falcão, Sócrates, Rivaldo e Juninho acreditam que serão o que desejam ser. Notadamente, dos cinco garotos, nenhum tem como ideal ser jogador de futebol. Fazer e trabalhar com alguma engenharia, faculdade de direito e exercer o cargo de advogado, juiz ou promotor, estudar arquitetura e tornar-se arquiteto, são as respostas que mantiveram uma linha de racionalidade entre o que se pretende e acredita ser.

Na fala dos outros participantes não houve tal coerência entre o desejo e a crença. Entre as respostas de Bebeto, Zico, Robinho, Ronaldo, Romário e Vampeta, apenas Ronaldo não mencionou querer ser futebolista. Contudo, os que mencionaram não acreditarem plenamente que serão. Ao justificar suas crenças, os garotos que querem ser futebolistas revelam:

\footnotetext{
"Eu pretendo jogar, ser jogador assim, e caso não dê certo fazer alguma faculdade. Acho que vou acabar fazendo faculdade mesmo". (Bebeto)

"Na melhor das hipóteses eu quero fazer faculdade. Na pior não sei, mas não descarto ser jogador de futebol, o problema é ter oportunidade". (Robinho)

"Meu pai é mecânico, então eu acho que vou acabar como ele". (Zico)
}

Um primeiro ponto de destaque é o fato da assimilação da ideia de "ser", com a profissão. Em outras palavras, em momento algum fora dito que a pretensão das perguntas era e tinha a ideia de função laboral futura. Quando se pergunta de modo geral em diálogos entre as pessoas, "o que você quer ser quando crescer?", as respostas conduzem a cargos e ocupações, mas pouco se contesta tal indagação com as projeções de estado de espírito ou postura de valores.

Consubstancialmente, o contexto criado no grupo focal interferiu o modo de resposta dos componentes, mas é inegável que as pressões sociais presentes no cotidiano das pessoas não nos encaminham a responder que, "quero ser feliz", "quero ser um exemplo de pai", "quero ser sinônimo de honestidade para meus amigos e familiares", mas sim replicar a 
que serviremos. Elencando-se subjetivamente que as pessoas hoje adultas, e muito possivelmente os jovens, priorizam suas funções laborais, do que como se sentirão com isso.

Durante a pesquisa, reconhecemos o exercício ético manifesto nos meninos, pois, uma vez sabedores da realidade dificultosa de inserção no mundo do futebol enquanto jogadores, não é de se lamentar que eles vislumbrem outros caminhos, carreiras e planos para se realizar e viver suas vidas, daí então o exercício do "ser ético". Segundo Cortella (2013), ser ético é a conduta regida por um conjunto de valores e princípios que utilizamos para tomarmos decisões nas várias situações da vida.

Neste ínterim, acreditamos que embora exista a paixão, sonho e querer na vida desses garotos - assim como de muitos outros - em se tornarem Ronaldos, Messis, Zidanes, existe ainda a consciência do desfrute, da realização e do protagonismo no futebol de outras maneiras, que não somente como jogadores, que não a todo e qualquer custo.

\section{ALGUMAS CONSIDERAÇÕES}

Consideramos que os jovens sujeitos desta pesquisa não se reconhecem como personagens que vivem um arco temporal, pois eles não se atrelaram à margem etária, caracterizando suas fases como momento de ensaio e preparação pelo que há de vir. De modo geral, ser jovem foi significado como aproveitar da vida, os momentos, as possibilidades, se colocando a dispor de experiências proveitosas que os ajudem a construir suas identificações e relações com o mundo.

A escola, por sua vez, foi significada como base para os futuros, como um espaço que prepara e oferta segurança à vida adulta, reconhecendo-a em sua função social formadora. Assim, pensar a escola significa pensar os futuros, na perspectiva de "ser alguém na vida", todavia, reconhecendo a divisão de pensares de alguns meninos entre estabelecer ou não uma relação de suas formações escolares com seus futuros pretendidos.

No que tange aos significados atribuídos ao futebol, foi percebido que alguns jovens significaram o esporte de modo peculiar em suas vidas, assim o futebol tomou forma em modos de socialização; paixão; descontração/lazer; também como possibilidade profissional pretendida, porém não acreditada. Enquanto quatro participantes significaram o futebol como um sonho, incorporando a possibilidade de valorização pessoal, social e financeira por intermédio do esporte.

A ideia de converter-se em futebolista se faz presente entre os meninos, pois evidenciamos o investimento temporal à prática, embora eles não consigam caracterizar de modo palpável todos os planos de ações que os façam configurarem entre os profissionais do futebol. De maneira análoga, seis dos entrevistados não apresentaram a correlação entre seus anseios futuros, abstendo-se da afirmação que serão o que desejam ser, mas, em sua maioria almejando a carreira de futebolistas.

Por outro lado, ao tratar de suas crenças e desejos sobre seus futuros, os participantes compreenderam a relação do futebol com o profissionalismo, relevadas nas respostas dos cinco meninos que serão o que desejam: mecânico, arquiteto, engenheiro, jurista e 
advogado, de modo que nenhum deles objetiva se tornar jogador de futebol. Com isso, observamos que embora o desejo de ser futebolista seja o mais presente para os jovens, tal desejo revela-se como o menos possível, deflagrando que as outras possibilidades fazem parte de projetos mais sustentáveis.

Por fim, com o presente estudo esperamos contribuir no âmbito social e acadêmico por tanger temáticas que necessitam cada vez mais de exploração e compreensão sobre o jovem/sujeito em processo de formação, bem como as crenças e projeções que permeiam o seu universo futuro. Nossa escolha de investigação e suas relações com a escola demonstram abranger os projetos de vida dos jovens ligados ai futebol, na mesma medida que deflagra uma necessidade de maior aprofundamento em suas discussões. Deste modo, reconhecemos algumas limitações na presente investigação, tais como a não extensão e prolongamento das entrevistas, contudo, acreditamos nas inúmeras possibilidades futuras para voltar a campo, na busca por aprofundar outros saberes e conhecimentos acerca dos jovens e seus projetos de vida.

\section{REFERÊNCIAS}

BARDIN, L. Análise de conteúdo. Lisboa: Edições 70, 1979.

BOGDAN, R.; BIKLEN, S. K. Investigação qualitativa em educação. Porto: Porto Editora, 1994.

CORTELLA, M. S. Não se desespere!: provocações filosóficas. 5. ed. Petrópolis-RJ: Vozes, 2013.

DAMO, A. S. Do dom à profissão: a formação de futebolistas no Brasil e na França. São Paulo: Aderaldo \& Rothschild, ANPOCS, 2007.

DAYRELL, J. T. O jovem como sujeito social. Revista Brasileira de Educação, n. 24, p. 40-52, set./dez. 2003.

FERREIRA, B. M.; BIANCONI, A. C.; COTTA, C. P.; COUTINHO NETTO, J. B.; BUFFO, M. M.; FREIRAS, M. B. Z.; SOUZA JÚNIOR, O. M.; MUNHOZ, R. F. $2^{\circ}$ Simpósio Internacional de estudos sobre Futebol: expressões, memórias, resistências e rivalidades. São Paulo. 2014.

FERREIRA, L. A.; SILVA, N. M.; GOES, A. T. R.. Jovens no contexto escolar: reflexões iniciais para a educação física. UNESP/Projeto do Núcleo de Ensino, Bauru, 2009. Texto para fins didáticos.

FERREIRA, L. A.; SANTOS, N. A.; VIEIRA, N. P.; RAMOS, G. N. S.. Ser jovem para os próprios (alunos) jovens. In: Encontro Nacional de Didática e Prática de Ensino, 2010, Belo Horizonte. Convergências e tensões no campo da formação e do trabalho doente: políticas e práticas educacionais... Belo Horizonte, 2010. p. 1-11.

GATTI, B. A. Grupo focal na pesquisa em ciências sociais e humanas. Brasília: Liber Livro Editora, 2005.

GIGLIO, S. S.; MORATO, M. P.; STUCCHI, S.; ALMEIDA, J. J. G. O dom de jogar bola. Horizontes Antropológicos. Porto Alegre, v.14, n. 30, p. 67-84, 2008. 
julho/2017

HALL, S. A centralidade da cultura: notas sobre as revoluções culturais do nosso tempo. Educação \& Realidade, Porto Alegre, v. 22, n. 2, p.15-46, jul./dez. 1997.

$\mathrm{KOCH}, \mathrm{R}$. Marcas da futebolização na cultura e na educação brasileira. 2012. 213 f. Dissertação (Educação) - Programa de Pós Graduação em Educação / Universidade Luterana do Brasil - ULBRA, Canoas, 2012.

LEÃO, G. M. P. L.; DAYRELL, J. T.; REIS, J. B. Juventude, projetos de vida e ensino médio. Educação \& Sociedade, Campinas, v. 32, n. 117, p. 1067-1084, 2011. Disponível em: < http://www.scielo.br/scielo.php?pid=S010173302011000400010\&script =s ci_arttext>.Acesso em: 15 nov. 2013.

NEGRINE, A. Instrumentos de coleta de informações na pesquisa qualitativa. In: MOLINA NETO, V. TRIVIÑOS, A.N.S (orgs.). A pesquisa qualitativa na educação física: alternativas metodológicas. Porto Alegre: Editora Universidade /UFRGS/Sulina, 1999. PERALVA, A. O jovem como modelo cultural. Revista Brasileira de Educação, n. 6, p. 15-24, set./out./Nov./dez., 1997. Disponível em: < http://anped.org.br/rbe/rbedigital/ RBDE05_6/RBDE05_6_04_ANGELINA_PERALVA.pdf >. Acesso em: 10 out. 2015

ROCHA, H. P. A.; BARTHOLO, T. L.; MELO, L. B. S.; SOARES, A. J. S. Jovens esportistas: profissionalização no futebol e a formação na escola. Motriz, Rio Claro-SP, v. 17, n. 2, p. 252-263, abr./jun. 2011. Disponível em: < http://www.scielo.br/pdf/motriz/ v17n2/04.pdf >. Acesso em: 06 abr. 2014.

SALVADOR, M. A S.; SOARES, A. J. G. A memória da Copa de 70: esquecimentos e lembranças do futebol na construção da identidade nacional. Campinas: Autores Associados, 2009.

SOARES, G. J. A.; MELO, S. B. L.; BARTHOLO, L. T.; ROCHA, A. P. H. Jovens esportistas: profissionalização no futebol e a formação na escola. Motriz, Rio Claro-SP, v. 17 n. 2, p. 252-263, abr./jun. 2011.

SOUZA JÚNIOR, O. M. Co-educação, futebol e Educação Física escolar. Dissertação (Mestrado em Ciências da Motricidade) - Departamento de Educação Física, Universidade Estadual Paulista, Rio Claro, 2003.

SOUZA JÚNIOR, O. M. Futebol como projeto profissional de mulheres: interpretações da busca pela legitimidade. 2013 (1-329). Tese de Doutorado. Universidade de Campinas, SP: 2013.

SOUZA JÚNIOR, O. M.; FERREIRA, B. M.; COUTINHO NETTO, J. B. Quem não sonhou em ser um jogador de futebol?: apontamentos sobre a formação de futebolistas na perspectiva de treinadores de categorias de base. Revista Mineira de Educação Física. Viçosa-MG, Edição Especial, n. 9, p. 920-925, 2013.

UNICEF. A infância entra em Campo. Riscos e oportunidades para crianças e adolescentes no futebol. Disponível em: http://www.unifec.org/brazil/pt/br_infanciaemcampo.pdf. Acesso em: 10 out. 2015.

Recebido em: julho/2016 Aprovado em: março/2017 